\title{
PULMONARY COLLAPSE IN PERTUSSIS
}

\author{
BY - \\ DAVID P. NICHOLSON, M.D., M.R.C.P. \\ Late Registrar to the Paediatric Unit, the County Hospital, Farnborough, Kent; Clinical Assistant \\ to Out-patients, Brompton Hospital, London
}

It is recognized that whooping-cough, or as it is better termed pertussis, is a frequent cause of chronic lung disease, though the actual nature of the morbid process is not always clearly understood. Articles on bronchiectasis frequently refer to pertussis as an antecedent illness, and this is also true of many articles on catarrhal lung, chronic bronchitis, and recurrent pneumonia, occurring in children. Bronchiectasis is ascribed to pertussis in a variable percentage of cases but there is less information available as to how many cases of pertussis develop bronchiectasis. This article deals with the case histories and radiographs of forty-four children who developed pertussis and who were followed in out-patients until free from symptoms and signs or until they were lost sight of. In this way an attempt has been made to follow the respiratory complications of pertussis to resolution, or until such changes as had occurred might be considered permanent. As it is not everywhere accepted that collapse of a lobe is a common complication of pertussis, and because there is as yet no general agreement that lobar collapse is the main cause of bronchiectasis, the theoretical considerations are first reviewed.

\section{Pertussis}

Pertussis was first described by Guillaume de Baillou in 1578. He named the disease Quinta or Quintana to indicate the tendency for the bouts of coughing to recur at five-hourly intervals. Cruickshank (1942) has reviewed the epidemiology of the disease and has given the overall mortality as $1 \cdot 26$ per cent. with a maximum mortality in the age group $0-2$ years of 3.7 per cent. In the five-year period 1943-7 notifications for England and Wales averaged 87,652 a year, and deaths 894 , or a mortality of a little over 1 per cent. In hospitals the mortality is higher; the L.C.C. hospital service recorded a mortality of 8.47 per cent. for the years 1929-32, whilst the combined Glasgow hospitals recorded a mortality of 27 per cent. for the years 1931-5. In this small series the mortality was 9.1 per cent. In the years 1929-32 pertussis was the fourth major cause of death in London in the age group 0-5 years, and Dingman (1946) in the U.S.A. gives pertussis as the third major cause of death in the age group
0-2 years. Mortality apart, the morbidity of the disease is high though there are few figures available to demonstrate this. Oswald (1947) states that serious pulmonary complications are to be expected in not less than 10 per cent. of cases.

The pulmonary collapse so often associated with pertussis has been variously ascribed to the enlargement of the mediastinal glands or to the plugging of the distal small bronchi and bronchioli with viscid sputum. Engel (1947) favours enlarged glands, but Kohn et al. (1944) could find enlarged glands in only five of 154 cases, and Oswald (1947) considers that enlarged glands are rare and play little part in the production of collapse associated with pertussis. Kohn et al. (1944), Feyrter (1927), Erb (1933), and Erwin (1939) have noted blocking of the terminal bronchioli by plugs of viscid sputum at autopsy, and Pospischill (1921) recorded the presence of bronchiectasis in practically all fatal cases of pertussis. Vining (1943) considers that pertussis is liable to leave behind a prolonged cough; of one hundred children with a chronic cough, ninety-two started their symptoms before the age of 5 , and in thirty-five the cough dated from an attack of pertussis. Vining (1943) and Oswald (1947) think that the main cause of such symptoms is collapse caused by blocking of the terminal bronchioli by plugs of viscid sputum. "The latter author found that collapse was more common in the left than the right lower lobe, that re-expansion was unlikely after six months, and that of forty cases where the lobe failed to re-expand bronchiectasis developed in thirty-eight. Ogilvie (1941) has observed that the collapse associated with pertussis may clear after the expectoration of a quantity of sputum. Lapin (1943) considers that bronchiectasis is a common complication, and that the obstruction of the bronchial tree is maximal at the bases, giving rise to cord-like and triangular shadows on the radiograph. Harries and Mitman (1947) agree, and stress the importance of the prolonged inspiration following the bout of coughing in displacing the sputum further into the lung. Hinshaw and Schmidt (1944) think that persistence of radiographic shadows indicates incipient bronchiectasis and that they should be watched until they disappear.

Kohn et al. (1944) thought that the pulmonary complications of pertussis were due to consolidated 'atelectatic' lung, and described the radiographic 
appearances in 222 children. In group one, consisting of 154 children who had little or no fever, coarse linear basal striations were seen in forty-eight, or 31.6 per cent., and consolidated lung in thirtyeight, or 24 per cent. In this group fifty-eight children were under the age of two; thirty-one had normal and twenty-seven abnormal radiographs. Ninety-six children were over the age of two, and the radiograph was normal in thirty-seven and abnormal in fifty-nine. The highest incidence of $x$-ray abnormalities was in the age group 3-5 years. In group two, children who had a fever of up to $101^{\circ} \mathrm{F}$., thirteen out of fifteen, or 86.6 per cent., had abnormal radiographs. Group three, the remainder, consisted of children who had a fever of over $101^{\circ} \mathrm{F}$., and forty-three of fifty-three, or 85 per cent., had abnormal radiographs. Re-expansion of collapsed areas usually occurred within fourteen days, and the majority of the collapsed areas were thought to be middle lobes.

\section{Bronchiectasis}

Collapse is probably a common complication of pertussis, and there is evidence that collapse may give rise to bronchiectasis, a condition that may be defined as any pathological dilatation of the bronchi and bronchioles beyond their normal size (Warner, 1935). Bronchiectasis was described in 1823 by Laennec, and in 1836 by Andral; both these authors commented upon its association with whoopingcough. Since then many theories have been postulated to explain the development of the disease, but until 1920 there was sufficient confusion between tuberculosis, fibroid lung, chronic pneumonia, and bronchiectasis, to render such speculations unprofitable. It is only in the last decades that the frequency of collapse and bronchiectasis has been recognized.

Louis in 1826 differentiated collapse from consolidation, and Alderson (1820), Bailey and Legendre (1846), and Gairdner (1850) commented upon the frequency of collapse in respiratory diseases. Heller in 1885 was perhaps the first to describe congenital atelectatic bronchiectasis and to provide a clear link between these two conditions. That collapse could be produced experimentally by blocking the bronchi was demonstrated by Traube in 1846, Mendelssohn in 1845, Lictheim in 1878. This has been confirmed more recently by Tannenberg and Pinner (1942), Lee-Lander and Davidson (1938), Adams and Escudero (1938), and Weinberg (1937).

The argument as to the ultimate cause of bronchiectasis still continues. Laennec (1823) thought that the dilation was due to the pressure of the retained secretions, and Andral (1836) incriminated the chronic cough, which in turn produced nutritional changes in the bronchial wall. Neither of these two theories bears close scrutiny today, though Adams and Escudero (1938), while discussing the importance of bronchial obstruction, conclude that this merely serves to dam up secretions, which produce the dilatation. They found experimentally that incomplete and not complete bronchial obstruction was associated with dilatation, a finding supported by the work of Tannenberg and Pinner (1942), and that the increased negative intra-pleural pressure associated with the collapse only affected the actual degree of dilatation and was not the basic cause. This view is difficult to uphold, and in any case complete bronchial obstruction would produce a better dam. It is unlikely that the weight of the secretions is sufficient to give rise to dilatation, and Wall and Hoyle (1932) have described cases of dry or uninfected bronchiectasis. Raymond in 1835 suggested that the strain of the constant cough would be sufficient of itself, and this view has been extended by Lemon (1926) to include the strain imposed by coughing upon a wall weakened by infection, a view supported by Thorpe (1929) and Marcy (1937). It is now agreed that the strain of inspiration and coughing is insufficient to cause dilatation unless there is a rise in intrapleural pressure from coincident lobar collapse. The bronchi are subject to atmospheric pressure on both sides of their lumen and the only variable factor is the intrapleural pressure.

Stokes in 1882 considered that the dilatation was a result of the neuromuscular paralysis of the bronchial wall secondary to infection. Corrigan in 1838 introduced the conception of traction upon the bronchial wall by fibrous tissue, a view supported by Findlay and Graham (1927). Warner (1935) disposes of fibrosis as a potential cause because dilatation is often seen without fibrosis, and because fibrosis might serve equally to compress as to dilate the bronchi. In 1843 Rilliet and Barthez had recorded a case of bronchitis that developed bronchiectasis within twenty-one days, and Perry and King (1940) consider that a collapsed lobe will always show bronchial dilatation long before fibrosis could have arisen.

The idea that hereditary influences may play a part in the causation of bronchiectasis was introduced by Hoffman, and recently Engel (1947) has gone to some lengths to produce evidence in favour of such a view. He considers that certain bronchi are constitutionally weak and are more likely to dilate. There is some evidence that vitamin deficiencies in pregnancy may lead to a maldevelopment of the finer bronchioles, and it would be premature to discard the influence of pre-natal factors altogether.

Leys (1927) writing on 'Chronic Pulmonary Catarrh,' reviews some of the literature and adds that the prevailing views at the time were either those of Laennec or of Corrigan. Leys (1927) describes chronic cough occurring after pertussis, and states that the disease lacks a name since it lacks a known etiology. In such cases he describes physical signs that might well be interpreted as those of collapse, yet he disputes the claim of Davidson that the condition is one of collapse associated with sinus infection, and he prefers to incriminate the 
$H$. influenzae of Pfeiffer as the causal agent, a view which he has almost certainly abandoned since.

At the present time opinions are divided as to the relative importance of collapse and infection in causing bronchiectasis. McNeil et al. (1929) have described a process of acute interstitial pneumonia of the bronchi that leads to necrosis and excavation followed by relining with epithelium and dilatation. Hedblom (1931) thinks that infection weakens the wall and that then mechanical factors dilate it. The infection precedes the collapse, which is the most important mechanical factor. Moll (1932) reviews the whole subject and decides in favour of infection being the causal agent. Infection destroys the wall which is then permanently dilated, though he does suggest that the first stage is one of loss of tone that may be temporary. Bronchial obstruction favours the infection. He describes fifty-five autopsies and thirty-seven patients, and as he often noted more extensive disease at autopsy than was evident during life he concludes that the disease is capable of spread. The infective theory is upheld by Erb (1933), Boyd (1931), and Robinson (1933). This last author examined sixteen lobectomy specimens and found that collapse played no part in the production of the dilatation, but that it favoured infection. Other writers, whilst agreeing that infection is the basic cause, consider that the collapse and the increase in negative intra-pleural pressure actually cause the dilatation (Vining, 1943; Hinshaw and Schmidt, 1944; Warner, 1935 and 1934; Wearing, 1948). In their comprehensive monograph on bronchiectasis Lisa and Rosenblatt (1943) find that the one factor common to all the diseases that cause bronchiectasis is infection, and that bronchial obstruction whether partial or complete is not the basic cause.

Gairdner in 1850 had suggested that obstruction of the bronchi by sputum might produce collapse. That this is possible has been confirmed in recent years by Kohn et al. (1944), Feyrter (1927), Erwin (1939), Ogilvie (1941), Jackson (1925, 1927, 1930), Archibald and Brown (1928), Lloyd (1931), Wall and Hoyle (1932), Anspach (1943), Warner (1934), and Lee-Lander and Davidson (1938). Oswald (1947) stresses the importance of this type of collapse and also the possibility of the sputum being sucked further in during inspiration. That this is a frequent cause of collapse is now realized, and concurrently the effects of bronchial obstruction have been more accurately defined. Complete obstruction of a main bronchus leads to distal collapse, since the gas tension in venous blood is $54 \mathrm{~mm}$. Hg. less than the alveolar gas tension, and the air distal to the block is slowly absorbed. In this type of obstruction there is collapse but no dilatation. Incomplete obstruction of a bronchus causes no collapse, but if the obstruction is ball valve then, depending on whether it is inlet or outlet in type, so emphysema or collapse will develop. Again there is usually no dilatation. If the obstruction is distal and many small bronchi and bronchioli are blocked, then the total anatomical effect is the same as in main bronchial obstruction, and the lobe collapses partly or totally. As a result of the collapse the intrapleural negative pressure increases and the bronchi proximal to the block are subjected to this increased force which, as the bronchi are now open to the atmosphere, dilates them. The weaker the walls from coincident infection, the more likely are they to dilate. In massive collapse the intrapleural negative pressure may reach $-423 \mathrm{~cm}$. of water (Jennings, 1937). It is as well to remember that the bronchi are incapable of dilating unless they are open to the atmosphere, and this accounts for the experimental findings previously noted that incomplete and not complete main bronchial obstruction is associated with dilatation. Theoretically incomplete main bronchial obstruction is not associated with dilatation, but there is always the possibility that particles of the obstructing agent may split off, be inspired deeper into the lung, and cause multiple distal bronchial obstructions. It is interesting to observe that in lipiodol bronchograms of dilated areas alveolar filling is not seen, presumably because the terminal bronchi are always obstructed.

This leads us to a consideration of the remaining theory of origin of bronchiectasis. Collapse is common and it is often caused by plugging of the small bronchi with sputum. Lobar collapse results in an increase of the negative intrapleural pressure that is capable of causing bronchial dilatation. In fact a collapsed lobe probably always contains bronchial dilatations. If the collapsed area should re-expand before irreparable damage has been done to the bronchial wall by infection, then the dilatation may disappear; such a sequence of events would account for the casès of reversible or 'pseudo-' bronchiectasis. If the collapse is maintained, so is the dilatation; and with chronic infection superimposed the dilatation becomes permanent to such an extent that it does not disappear if the collapsed area should now re-expand. Oswald (1947) states that re-expansion of a collapsed lobe is unlikely after six months. Anspach (1933) observed forty children with bronchiectasis all of whom had triangular basal shadows on the radiographs, and he thought that the collapse was the main cause of the dilatation. Wall and Hoyle (1932) described cases of dry bronchiectasis which they thought were due to the dilating force of inspiration when the small bronchi were blocked. Anspach (1934) states that the longer the duration of the collapse the more likely is bronchiectasis to develop. Ellis (1933) describes the sequence as collapse then dilatation, and Miller (1934) quotes Schneider (1927) as saying that bronchiectasis is preceded by a purely dilated state in which there is a simple atrophy of the wall. King (1937) observed dilatation in a lobe five days after operation and discards collapse as a cause since the dilatation occurred too quickly, an occurrence that is not impossible if collapse is the cause of the dilatation. Lee-Lander and Davidson (1938), by blocking the distal bronchi, were able to 
produce bronchiectasis in a cat. The degree of dilatation was less if an artificial pneumothorax was subsequently induced. In twenty patients with bronchiectasis they noted that the calibre of the bronchi varied more on inspiration and expiration than did that of a normal bronchus. Greenfield (1940) did not agree with this last finding, which Lee-Lander and Davidson had given as a point in favour of the bronchial wall being intact but dilated. Erwin (1939) supports the collapse theory and agrees that in the early stages the condition may ${ }_{\triangleleft}$ be reversible. Andrus (1940) regards any chronic basal pneumonia as suspicious of bronchiectasis, as are increased basal striations if vascular congestion be excluded. Displacement of organs toward the diseased area occurred in 90 per cent. of cases and confirmed the association with collapse; major atelectasis, if chronic, is virtually diagnostic of bronchiectasis. He continues by saying that pneumonia regularly undergoes resolution so long as there is no collapse; if there is collapse then dilatation results from the enhanced pull of the lung. Oswald (1947) and Wearing (1948) agree, and Kornblum (1944), whilst adhering to the infective theory of origin, states that should it be demonstrated that the disease is reversible then our whole concept of the disease must be altered, presumably in favour of collapse as the main etiological agent. Wearing (1948) reports such an instance of reversible bronchiectasis but complains that the literature contains few references.

Reversible bronchiectasis. If bronchiectasis is reversible up to a certain stage in the disease process, then it is reasonable to assume that the bronchial wall has not been permanently damaged by infection and that the muscle and elastic layers are intact. Lee-Lander and Davidson (1938) have given reasons for believing that in fact the wall is intact. In some instances a collapsed area is seen to re-expand and still leave dilatation: this would be possible if, subsequent to the dilatation, infection had ensued and irreparably damaged the wall. Dilatation may be observed in a collapsed lobe or segment at an early date, before it would be possible for infection to have destroyed the wall. If infection followed by destruction is the cause of the dilatation then the condition must surely be irreversible. There are several references in the literature to reversible or 'pseudo' bronchiectasis (Erwin, 1939; Ogilvie, 1941; Moll, 1932; Robinson, 1933; Greenfield, 1940; Andrus, 1940; Kornblum, 1944). Lisa and Rosenblatt (1943) and Hinshaw and Schmidt (1944) regard such reversible dilatation as an illusion created by the temporary crowding and foreshortening of the bronchi in a collapsed lobe. Such a criticism eradicates bronchiectasis as a disease entity and can hardly be taken seriously. Oschner (1929) mentions four cases of reversible bronchiectasis but gives no details. Wearing (1948) describes one case and asks, ' How long does it take reversible bronchiectasis to become irreversible ?' Oswald (1947) suggests that the time is six months. Several examples of reversible bronchiectasis have been gleaned from the literature, and a summary of these appears in table 1. Blades and Dugan (1944) discuss four other cases but give no details except that the bronchi returned to normal in three months, and they suggest that this may still happen after

TABLE 1

SURVEY OF CASES OF REVERSIBLE BRONCHIECTASIS OCCURRING IN THE LITERATURE

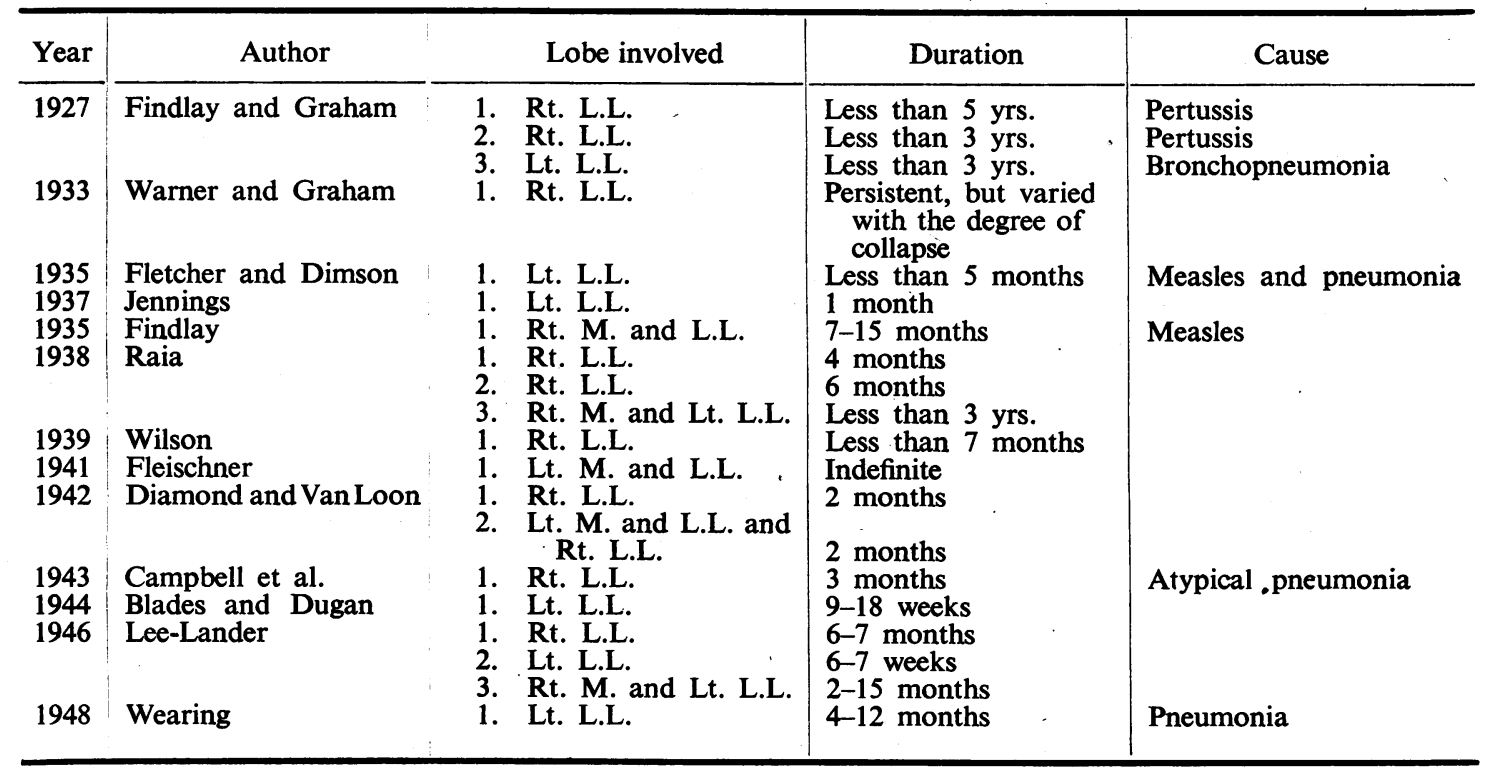




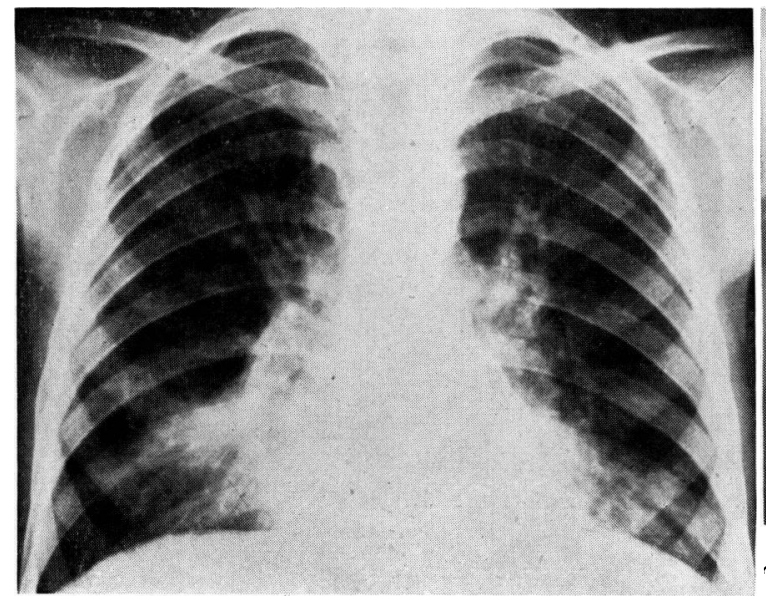

FIG. 1.

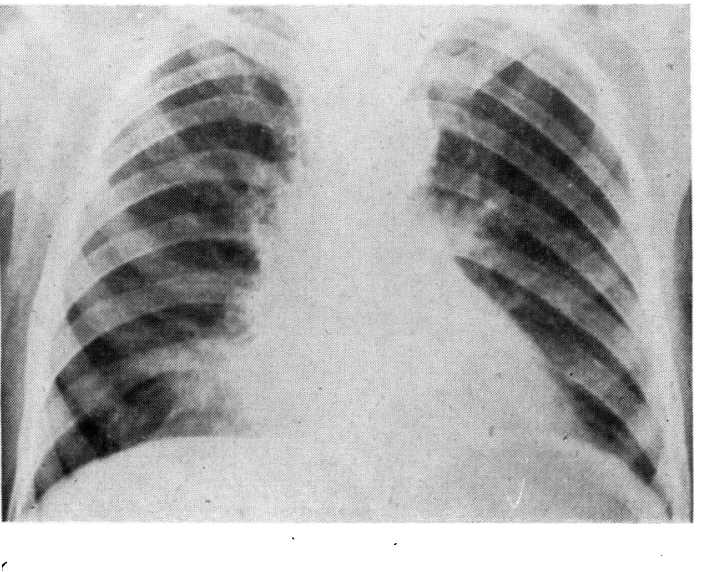

FIG. 2.

Fig. 1.-Case 6: radiograph taken on Feb. 5, 1948, of a boy aged five years. The illness was in the acute stage and there was bilateral lower and right middle lobe collapse.

Fig. 2.-The same case on March 19, 1948, showing collapse of the right middle lobe.

FIG. 3.-The same case: a bronchogram taken on April 1, 1948, showing collapse and dilatation of the right middle lobe.

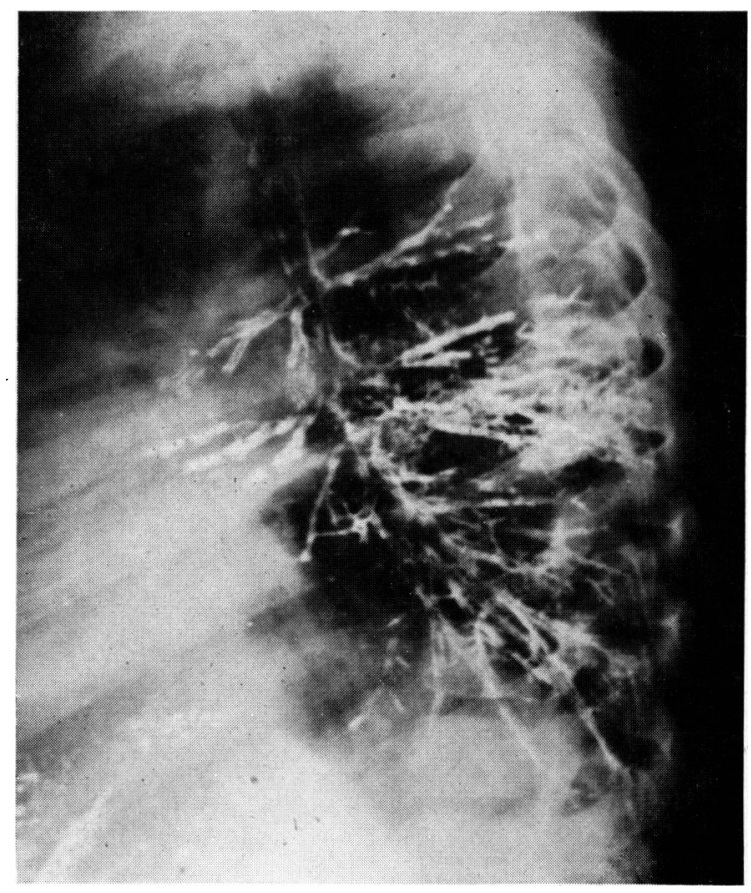

FIG. 3. 

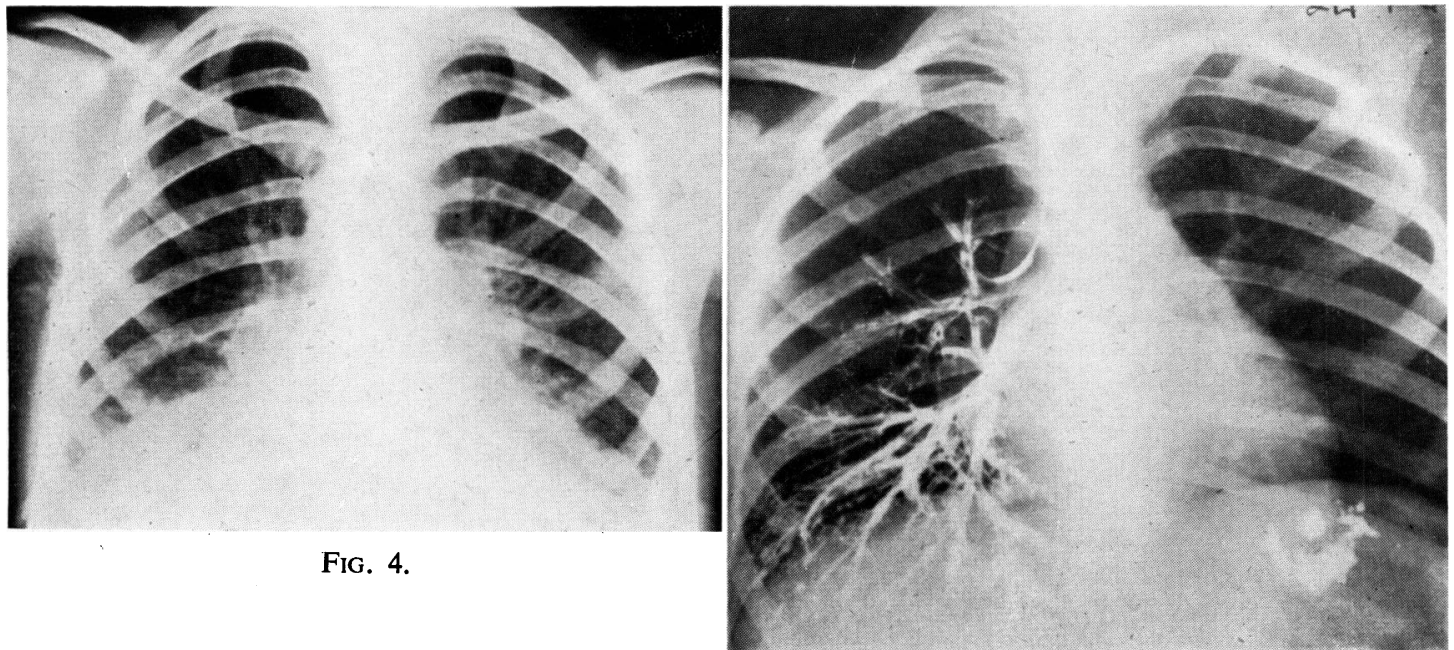

FIG. 5.

FIG. 4.

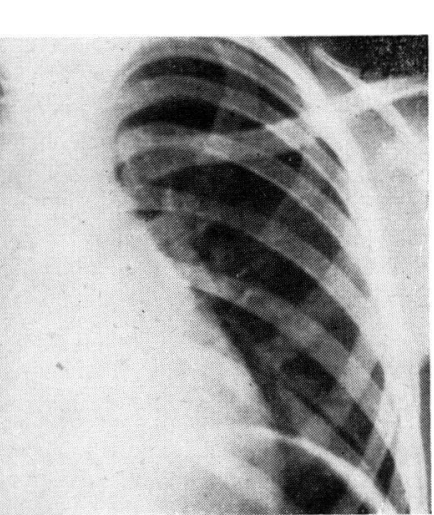

FIG. 4.-Case 11: radiograph taken on June 26, 1947, of a girl aged four years. The illness was in the acute stage and there was collapse of the right lower lobe (possibly the left as well).

FIG. 5.-Bronchogram of the same case taken on July 24, 1947, showing dilatation of the posterior basic branches of the right lower lobe.

FIG. 6.-A clear radiograph. of the same case taken on Jan. 21, 1948.

FIG. 7.-Case 15: a boy aged four years. The radiograph, taken on April 17, 1947, in the acute stage, shows collapse of the left lower lobè.

Fig. 8.-The same case on March 17, 1948. Collapse of the left lower lobe is still present.

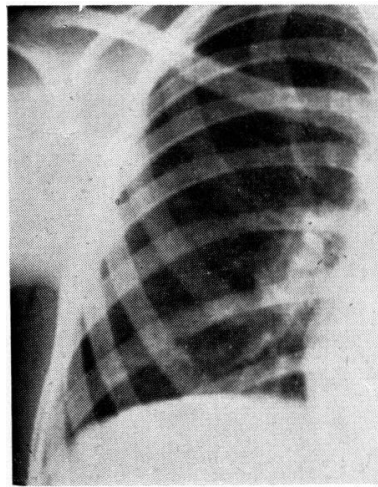

FIG. 6.

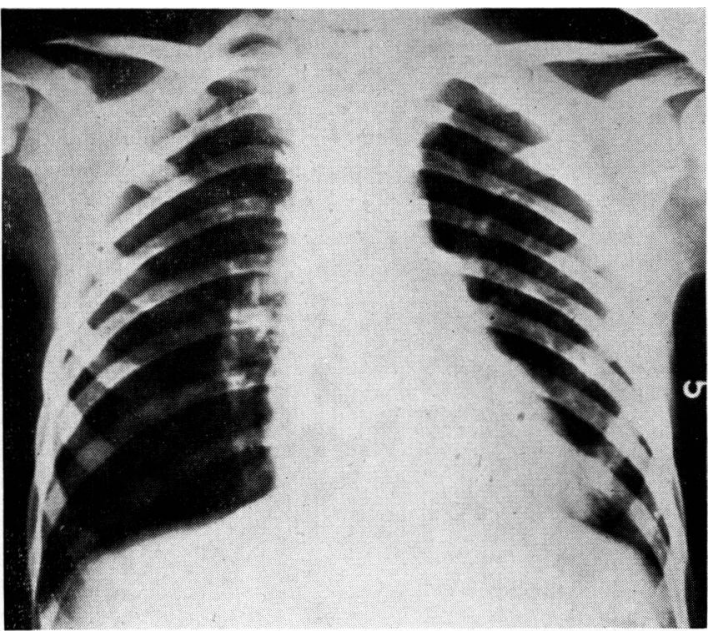

FIG. 7.

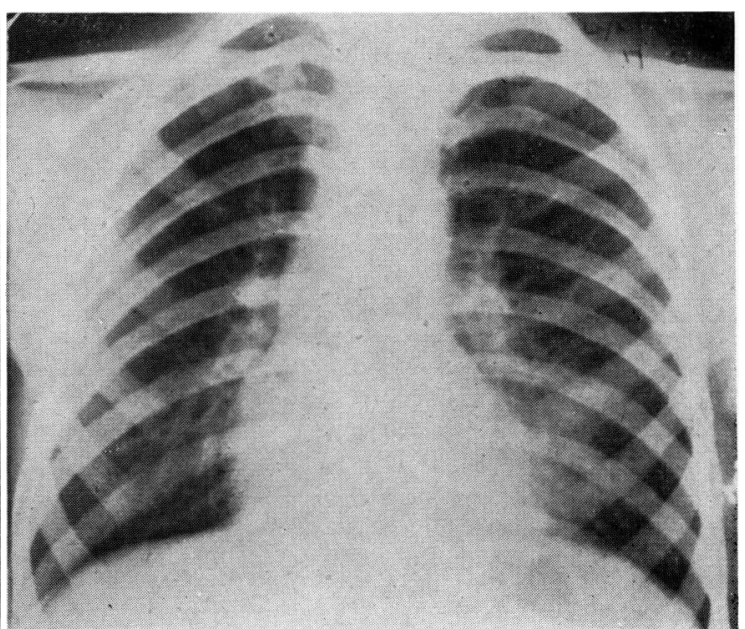

FIG. 8. 


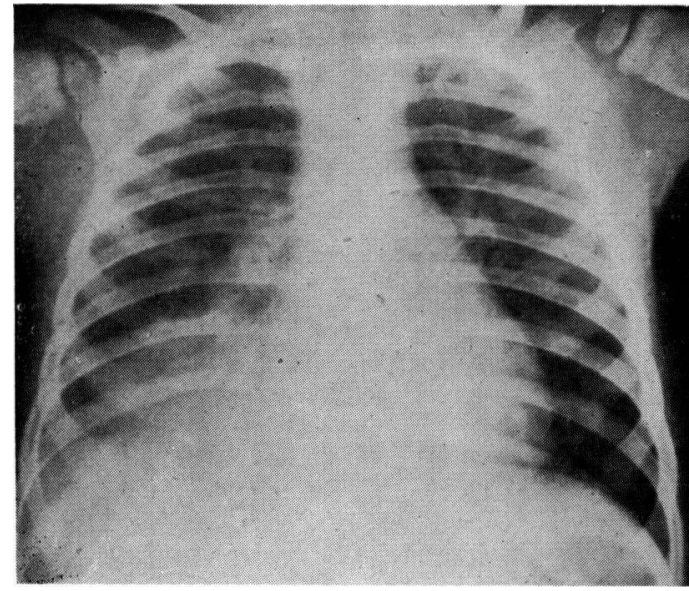

FIG. 9.-Case 19: a boy aged one year. The radiograph, taken on April 3, 1947, in the acute stage, shows collapse of the right lower lobe.

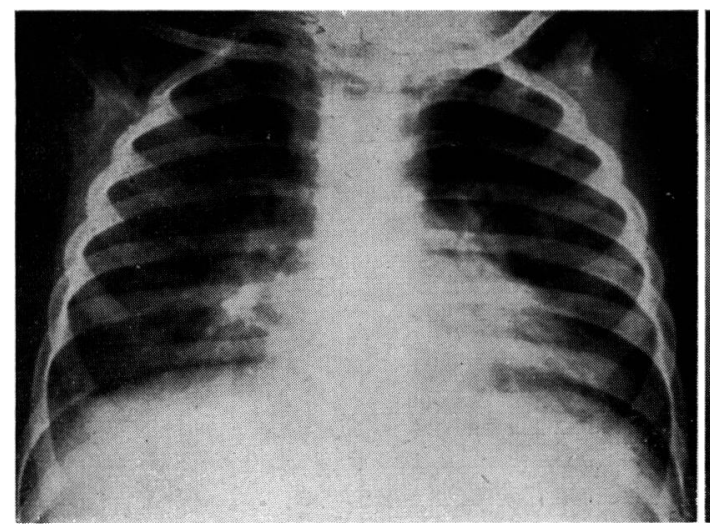

Fig. 11.-Case 7: a boy aged five years. A radiograph taken on May 2, 1947, during convalescence, showing collapse of the lower and right middle lobes.

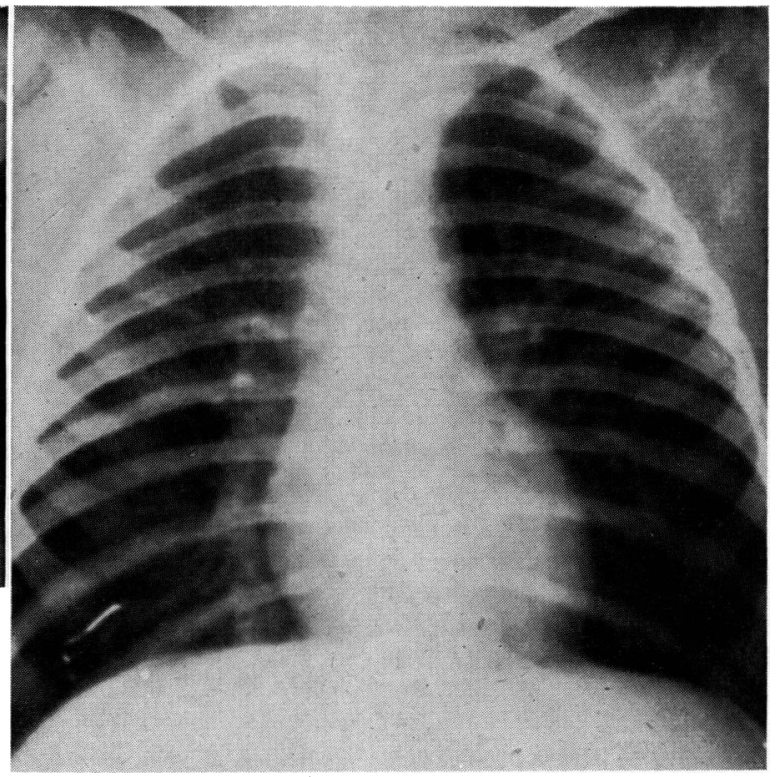

FIG. 10.-A clear radiograph of the same case taken on Feb. 25, 1948. 
three months. In these examples, where a second bronchogram was done reasonably soon after the first, the dilatation had lasted roughly six months or less. This suggests that if the collapse is more permanent the dilatation becomes irreversible.

If collapse is the cause of bronchiectasis then spread of the process should not arise unless an intercurrent disease occurs that is capable of initiating further collapse. Churchill and Belsey (1939) and Perry and King (1940) consider that spread is unusual unless this should occur.

Clinical observation of cases of postoperative massive collapse lends further support to the view that viscid sputum may lead to blocking of the bronchi and collapse (Pasteur, 1908, 1914; Bradford, 1918; Briscoe, 1914, 1919; Sante, 1927; Findlay, 1932; Scott, 1925; Elliot and Dingley, 1914; Corrylos and Birnbaum, 1928).

Anatomy. A detailed knowledge of the anatomy of the bronchi is important if the full effects of bronchial obstruction are to be understood. The anatomy of the bronchi has been described by Ewart (1889), Kramer and Glass (1932), Neil et al. (1937 a and b), Nelson (1934), and more recently by Brock (1942-3-4) and Foster-Carter (1942). The size of the bronchi has been estimated by Engel (1947) and Miller-(1947). The diameter of the bronchi at birth is given as $5.7 \mathrm{~mm}$. in the coronal, and $6.0 \mathrm{~mm}$. in the sagittal plane. By adult life these measurements are $16.5 \mathrm{~mm}$., and $14.4 \mathrm{~mm}$. respectively. The terminal bronchioles measure $0.12 \mathrm{~mm}$. at three months and $0.20 \mathrm{~mm}$. in diameter by adult life. Kohn and others (1944) found that in pertussis respiratory complications were most frequent in the age group 3-5 years. If size alone were the only consideration then it would be expected that the bronchi of infants would be blocked more frequently. This does not appear to be so, and it may be that the bronchial glands, which are immature at birth, are incapable of secreting sufficient mucus until early childhood. In childhood the goblet cells are well developed but they are never present in bronchi with a diameter of less than $0.4 \mathrm{~mm}$.

Radiography. Ewart in 1889 introduced the idea of constant broncho-pulmonary segments, areas composed of a framework of small bronchi whose trunk is an offshoot of a lobar bronchus. This conception has been amplified by Kramer and Glass (1932) and Foster-Carter and Hoyle (1945). Collapse of a broncho-pulmonary segment throws a shadow on the radiograph that is relatively constant, and with the aid of lateral views the area may be defined. Interpretation of radiographs plays an important part in the control and assessment of cases of pertussis. It has been assumed that the triangular basal shadows so frequently seen on radiography represent collapsed lower lobes. In the past these shadows have been variously interpreted as indicating pneumonia, mediastinal pleurisy, or fibrosis. In 1926 Singer and Graham noted that these shadows were often associated with bronchiectasis, and at operation they found that the lower lobes were collapsed. This has been confirmed by Warner (1935), Warner and Graham (1933), Ogilvie (1941), Riggins (1941), Findlay (1935), Anspach (1934), and Andrus (1940), and it has been observed that in these cases the distal small bronchi are often plugged with sputum (Anspach, 1939; Warner and Graham, 1933). Triangular basal shadows were noted in 6 per cent. of cases of bronchiectasis by Warner and Graham (1933), in twenty-seven of sixty-eight cases by Ogilvie (1941), and in 17 per cent. of cases by Joress and Robins (1944). If the collapse is lobar then compensatory emphysema of the adjacent healthy lung, and mediastinal shift, occur.

\section{Relation of Pertussis to Bronchiectasis}

Articles on bronchiectasis often refer to pertussis as an antecedent and causal illness. Table 2 gives a list of such references with the percentage incidence given, pertussis being an antecedent illness in an average of 14 per cent. of cases.

TABLE 2.

ARTICLES ON BRONCHIECTASIS REFERRING TO PERTUSSIS AS AN ANTECEDENT ILLNESS

\begin{tabular}{l|r}
\hline \multicolumn{1}{c|}{ Authors } & Percent. of casesaffected \\
\hline Warner (1935) & 4 \\
Diamond and van Loon (1942) & 8 \\
Thorpe (1929) & 26 \\
Raia (1938) & 21 \\
Perry and King (1940) & 9 \\
Oswald (1947) & 14 \\
Ogilvie (1941) & 8 \\
Lemon (1926) & 46 \\
Moll (1932) & 9 \\
Joress and Robins (1944) & 8 \\
Hedblom (1931) & 9 \\
Graham et al. (1935) & 11 \\
Findlay and Graham (1927) & 9 \\
Boyd (1931) & 9 \\
\hline \multicolumn{1}{c|}{ Average } & 14 \\
\hline
\end{tabular}

In this discussion it has become evident that collapse is a common complication of respiratory diseases, and that it is almost certainly the forerunner if not the actual cause of bronchial dilatation.

In uncomplicated pertussis with few or no signs of secondary respiratory infection the radiograph is often normal and enlargement of the mediastinal glands is not seen. If such glandular enlargement is seen it is highly suspicious of a coincident primary tuberculous infection. If there are signs and symptoms of secondary infection of the respiratory tract, then abnormal $x$-ray shadows become increasingly frequent. The abnormal shadow is often typical of lobar or segmental collapse. Clinically the physical signs usually support such a 
diagnosis, and as a rule neither the signs nor the radiographic appearances respond to chemotherapy in the manner of a classical- lobar or bronchopneumonia, a fact borne out by the investigation of Kohn, Rubin, and Hobart (1940). Pyrexia and cough tend to continue until the radiograph is clear, and it is probable that the majority of respiratory complications in pertussis are due to lobar or segmental collapse. Collapse will be more likely if there is secondary infection and excess secretion of mucus, particles of which tend to be inspired deeper into the lung and to block the small bronchi and bronchioli. The collapse is due to the blocking of the terminal bronchi, and this was evident in three of the autopsies in this series. The alveoli become airless, the lobe diminishes in size, the negative intrapleural pressure increases, and the bronchi proximal to the block undergo compensatory dilatation; this is reversible in the first instance but becomes permanent if the area fails to re-expand or if infection supervenes. If the collapsed area should re-expand then the dilatation may disappear. After six months or so this becomes increasingly unlikely, and such a possibility probably depends upon the degree of infection present.

\section{Present Investigation}

The present series consists of forty-four children suffering from pertussis who were in most instances sufficiently ill to warrant admission to hospital. There were twenty-three girls and twenty-one boys. The duration of symptoms before admission was less than one week in thirteen, or 29.5 per cent., and more than one week in thirty-one, or 70.5 per cent. The age incidence is shown in table 3. This

TABLE 3

AGE INCIDENCE IN FORTY-FOUR CHILDREN WITH PERTUSSIS ADMITTED TO HOSPITAL

\begin{tabular}{c|c|c|c|c|c|c|c}
\hline & $\begin{array}{c}0-6 \\
\text { mths. }\end{array}$ & $\begin{array}{c}6-12 \\
\text { mths. }\end{array}$ & $\begin{array}{c}1-2 \\
\text { yrs. }\end{array}$ & $\begin{array}{c}2-3 \\
\text { yrs. }\end{array}$ & $\begin{array}{c}3-4 \\
\text { yrs. }\end{array}$ & $\begin{array}{c}4-5 \\
\text { yrs. }\end{array}$ & $\begin{array}{c}5-8 \\
\text { yrs. }\end{array}$ \\
\hline $\begin{array}{c}\text { No. } \\
\text { deaths }\end{array}$ & 1 & 4 & 5 & 9 & 5 & 7 & 6 \\
& 0 & 0 & 1 & 2 & 0 & 0 \\
\hline
\end{tabular}

gives an overall mortality of $9 \cdot 1$ per cent. During their stay in hospital, and subsequently as outpatients these children were examined frequently both clinically and by radiograph. Five children, or 11.4 per cent. (three boys and two girls) revealed no x-ray abnormality at any time. The rest had at some time abnormal signs both physically and radiographically. It is, of course, possible that some transient radiographic changes occurred unnoticed.

The shadows seen on the radiographs were usually typical of lobar or segmental collapse, mainly of the middle and lower lobes. Evidence in favour of the shadows representing collapsed lobe was as follows: (1) physical signs of collapse and lack of response to chemotherapy; (2) association of mediastinal shift and compensatory emphysema; (3) the presence in some radiographs of visibly dilated bronchi in the shadow; (4) the similarity of the shadows with the triangular basal shadows 'previously discussed.

As far as possible the children were divided into three groups. Group one was composed of mild cases with few or no signs of respiratory infection and little or no pyrexia. Group two, cases of moderate severity with signs of secondary infection and pyrexia of up to $101^{\circ} \mathrm{F}$. Group three, severe with marked signs of secondary infection and pyrexia of over $101^{\circ} \mathrm{F}$, and a prolonged course to recovery. Four children died, and all were classified as severe cases. Case 13, a girl aged two, showed collapse of both lower and the right middle lobes on radiography, and this was confirmed at autopsy when the distal small bronchi were seen to be blocked by plugs of sputum. A similar state of affairs was seen in a girl aged three, Case 23, who in life showed bilateral lower-lobe collapse, which was confirmed at autopsy, and in Case 26, a boy aged seven weeks, who had shown bilateral lower-lobe collapse as well. Case 31, a girl aged three, died soon after admission and autopsy revealed an extensive bilateral bronchopneumonia. Four cases were mild, sixteen, or 36.4 per cent. were classified as moderate, and twenty-four, or $54 \cdot 5$ per cent., as severe (table 4 ).

TABLE 4

DEGREE OF SEVERITY IN THE PRESENT SERIES

\begin{tabular}{l|c|c|c|c|c}
\hline \multicolumn{1}{c|}{ Age } & No. & Mild & Moderate & Severe & Deaths \\
\hline 0-6 mths. & 8 & 1 & 4 & 3 & 1 \\
6-12 ", & 4 & 0 & 3 & 1 & 0 \\
$1-2$ yrs. & 5 & 0 & 1 & 4 & 0 \\
$2-3, "$ & 9 & 2 & 2 & 5 & 1 \\
$3-4, "$ & 5 & 0 & 2 & 3 & 2 \\
$4-5, "$ & 7 & 1 & 3 & 3 & 0 \\
$5-8, "$ & 6 & 0 & 1 & 5 & 0 \\
\hline Total . & 44 & 4 & 16 & 24 & 4 \\
\hline
\end{tabular}

There was no evidence of collapse in one out of four mild cases, three out of sixteen moderate cases, and one out of twenty-four severe cases; on the other hand collapse of over two months' duration was seen in one out of four mild cases, nine out of sixteen moderate cases, and thirteen out of seventeen severe cases, that were followed for a sufficient length of time. The collapse was bilateral in eighteen: the right upper lobe was involved once, the right middle lobe ten times, the right lower lobe thirty-five times, the left lingula five times, and the left lower lobe nineteen times. This preponderance of right- over left-sided collapse is unusual, though it will be appreciated that left lower-lobe collapse is more difficult to diagnose. Oswald (1947) noted left lower-lobe collapse twenty-eight times to eighteen times on the right, Diamond and Van Loon (1942) an incidence of fifteen to twelve, and Campbell 
et al. (1943) an equal incidence in seventy-eight cases. The reasons offered for the greater frequency of left-sided collapse are that the left main bronchus arises at a more acute angle and that it is in intimate relationship with the arch of the aorta and the pulmonary artery. From the foregoing theoretical considerations it would be expected that collapse would have an equal incidence on both sides, and it is difficult to explain this apparent anomaly.

TABLE 5

INCIDENCE OF COLLAPSE IN PRESENT SERIES

\begin{tabular}{c|c|c}
\hline Age & $\begin{array}{c}\text { Collapse of over } \\
\text { two months }\end{array}$ & No collapse \\
\hline $0-6$ mths. & 2 out of 7 & 2 out of 8 \\
$6-12,$, & 2 out of 4 & 2 out of 4 \\
$1-2$ yrs. & 2 out of 3 & 0 out of 5 \\
$2-3,$, & 4 out of 8 & 1 out of 9 \\
$3-4$, & 2 out of 3 & 0 out of 5 \\
$4-5$, & 7 out of 7 & 0 out of 7 \\
$5-8$, & 4 out of 6 & 0 out of 6 \\
\hline
\end{tabular}

Collapse of a serious nature seems to be more frequent in childhood than in infancy, a fact corroborated by Kohn et al. (1944). In all collapse occurred in thirty-nine out of forty-four cases, a high incidence (table 5).

Lee-Lander (1936) says that in the collapse following the infectious fevers no prognosis can be given since our knowledge of the condition is insufficient. The duration of the collapse varies; the more severe examples tend to last longer. Of the cases that were followed until clear or for longer than a year, thirty-five of forty-eight collapsed lobes had re-expanded within nine months; thereafter no further re-expansion was seen during the time of observation. It is probable that no further re-expansion will occur after nine months; the collapse is now permanent and dilatation established. Thirty-three children were followed for more than one year, and seven still had a collapsed lobe. If bronchiectasis is a possible end result in 21 per cent. of cases of severe pertussis then treatment must be started early. Only three out of fourteen cases admitted in the first week of the disease developed serious pulmonary complications, whereas nineteen out of twenty-seven cases admitted after the first week developed such complications.

Treatment. The early diagnosis of pertussis is difficult, and in any case there is no specific treatment. Aerosporin, a new drug, is obtained from the B. Aerosporus, and it will inhibit $\mathrm{H}$. Pertussis in a minimal dilution of $0.04 \mu \mathrm{g}$ per ml. (Ainsworth and others, 1947; Brownlee and Bushby, 1948). In some cases in this series Swift (1948) gave $0.8 \mathrm{mg}$. per $\mathrm{kg}$. four-hourly, and from his series he concluded that a response was usual within twenty-four hours, but that the ultimate benefit seemed to depend on the duration of symptoms before the start of treatment rather than upon the severity of the disease itself. If aerosporin is given before secondary infection has caused collapse then the pulmonary complications might be averted, though in this series the small number of cases who had aerosporin differed in no way from the others. Excluding specific treatment, sulphonamides and/or penicillin should be given to avert or reduce secondary infection, and such measures may prevent further collapse. In a few cases inhalations of penicillin were tried, using either a 'Deedon' or -Aerosol' inhaler and a mixture of carbon dioxide and oxygen. Results were unsatisfactory as children do not tolerate a mask or tent well, but further trials would be justified.

If collapse is still present after the acute stage is over further treatment is imperative, and should be directed at the collapsed lobe. Postural drainage in the appropriate position should be given (Nelson, 1934), and this should be combined with percussion over the affected lobe in an attempt to induce the child to cough up the particles of sputum. Treatment in this manner can be given several times a day and must be given until all hope of re-expansion is abandoned, after six or nine months. It may even be continued at home under the guidance of the parents.

It will be seen from fig. 13 that the likelihood of re-expansion becomes less after six months, and

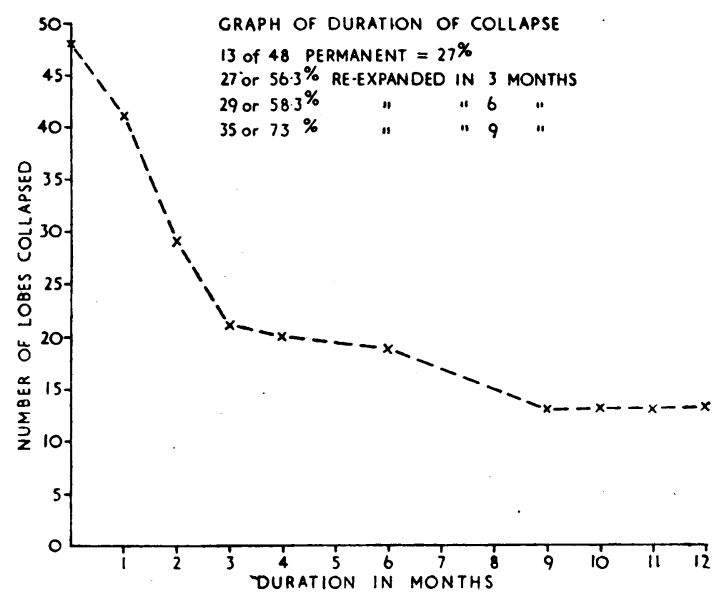

Fig. 13.

improbable after nine months. After this time it can be assumed that collapse is established and that bronchial dilatation is likely to be permanent. In such cases clinical symptoms of infected bronchiectasis may occur, with cough and productive sputum. If this state of affairs continues the need for surgery may arise, and at this stage complete bilateral bronchograms must be done to define the extent of the bronchial dilatations. In this series bronchograms were done on three children. Case 6, a boy aged five years, had collapse of both lower 
lobes and the right middle lobe. After ten weeks the middle lobe was still collapsed and a bronchogram showed dilatation and crowding of the middle lobe branches (fig. 3). Case 11, a girl aged four years, had a collapsed right lower lobe; after three weeks this had not completely re-expanded and a bronchogram revealed dilatation of the posterior basic branches (fig. 5). Subsequently the lobe re-expanded completely. Case 36, a girl aged four years, had bilateral basal collapse that cleared in eight weeks; a subsequent bronchogram was normal.

Following an attack of pertussis a child may continue to suffer from cough, which may be paroxysmal, and attacks of bronchitis. The examination and radiograph of these children usually reveals a collapsed lobe. If treatment is inadequate and fails to produce re-expansion, the cough continues and eventually may merge with the symptoms of bronchiectasis. Many of these cases still go unrecognized, and all too often the treatment consists of an ineffective cough mixture.

\section{Summary}

The literature relating to pertussis and bronchiectasis has been reviewed. It has been concluded that pulmonary collapse is a common feature of pertussis, and that if re-expansion does not occur within nine months it is unlikely to do so, and bronchiectasis may supervene. Treatment of these cases must be prolonged and efficient. Postpertussis pulmonary collapse is often still unrecognized.

My thanks are due to Dr. F. H. Hackwood, Surgeon Superintendent, for permission to publish this article, and to Dr. D. Leys and Dr. P. N. Swift for their advice and help.

\section{REFERENCES}

Adams, W. E., and Escudero, L. (1938). Tubercle, 19, 351.

Ainsworth, G. C., Brown, A. M., and Brownlee, G. (1947). Nature, 160, 263.

Alderson, J. (1820). Medico-Chirurgical Trans., 16, 78. Andral(1836). Clinique Medicale. Trans. D. Spillane, London.

Andrus, P. M. (1940). Amer. Rev. Tuberc., 41, 87, 99, 104.

Anspach, W. E. (1934). Amer. J. Dis. Child., 47, 1011.

- (1939). Amer. J. Roentgen., 41, 173.

(1943). Dis. Chest, 9, 24.

Archibald, E., and Brown, A. L. (1928). Arch. Surg., 16, 322.

Bailey, P, and Legendre, F. L. (1846). Obstet. Soc., Paris.

Blades, B., and Dugan, D. J. (1944). J. Thorac. Surg., $13,40$.

Boyd, G. L. (1931). Canad. med. Ass. J., 25, 174.

Bradford, J. R. (1918). Quart. J. Med., 12, 127.

Bradford, (1914). Lancet, 1, 1502.

Briscoe, J. C. (1919). Quart. J. Med., 13, 293.

(1914). Lancet, 1, 1502.
Brock, R. C.(1942). Guy's Hosp. Rep., 91, 111. (1943). Ibid., 92, 26; 92, 123.

(1944). Ibid., 93, 90.

Brown, A. L. (1931). Arch. Surg., 22, 976.

Brownlee, G., and Bushby, S. R. M. (1948). Lancet, $1,127$.

Campbell, T. A., Strong, P. S., Grier, G. S., and Lutz, R. J. (1943). J. Amer. med. Ass., 122, 723.

Churchill, E. D., and Belsey, R. (1939). Ann. Surg., $109,481$.

Corrigan, D. J. (1838). Dublin. J. med. Sci., 13, 266.

Corrylos, P. N., and Birnbaum, G. L. (1928). Arch. Surg., 16, 501.

Cruickshank, R. (1942). Control of Common Fevers. Lancet. London.

Dingman, H. (1946). Risk Appraisal. National Underwriter Corporation. Cincinnati.

Diamond, S., and van Loon, E. L. (1942). J. Amer. med. Ass., 118, 771.

Elliot, T. R., and Dingley, L. A. (1914). Lancet, 1, 1305.

Ellis, R. W. B. (1933). Arch. Dis. Childh., 8, 35.

Engel, S. (1947). The Child's Lungs. 'First Edit. London.

Erb, I. H. (1933). Arch. Path., 15, 357.

Erwin, G. S. (1939). Brompton Hos. Rep., 8, 43.

Ewart, W. (1889). The Bronchi and Pulmonary Blood Vessels. London.

Findlay, L. (1935). Arch. Dis. Childh., 10, 61. (1932). Proc. R. Soc. Med., 25, 407.

—, and Graham, S. (1927). Arch. Dis. Childh., 2, 71.

-, (1931). Ibid., 6, 1.

Feyrter, F. (1927). Frankfurt. Z. Path., 35, 213.

Fleischner, F. G. (1941). Amer. J. Roentgen., 46, 166.

Fletcher, E., and Dimson, S. B. (1935). Lancet, 1, 987.

Foster-Carter, A. F. (1942). Brit. J. Tuberc., 36, 19.

-, and Hoyle, C. (1945). Dis. Chest., 11, 511 .

Gairdner, W. T. (1850). Monthly J. med. Sci., 11, 135.

Graham, E. A., Singer, J. J., and Ballon, H. C. (1935). Surgical Diseases of the Chest. London.

Greenfield, J. (1940). J. clin. Invest., 19, 723.

Harries, E. H. R., and Mitman, M. (1947). Clinical Practice in Infectious Diseases. Third Edit. Livingstone. Edinburgh.

Hedblom, C. A. (1931). Surg. Gynec. Obstet., 52, 406.

Heller, A. (1885). Dtch. Arch. Klin. Med., 36; 189.

Hinshaw, H. C., and Schmidt, H. W. (1944). Dis. Chest, 10, 115 .

Holinger, P., and Andrews, A. H. (1941). Amer. J. Surg., 54, 193.

Jackson, C. (1925). Ann. Surg., 72, 364.

Jackson, (1927). Bronchoscopy and Oesophagoscopy. Second Edit., p. 301. Philadelphia. (1930). J. Amer. med. Ass. 95, 639.

Jennings, G. H. (1937). Brit. med. J., 2, 963.

Joress, M. H., and Robins, S. A. (1944). Dis. Chest, 10, 489 .

King, D. S. (1937). Internat. Clin., 1, 130.

Kohn, J. L., Schwartz, I., Greenbaum, J., and Daly, M. M. I. (1944). Amer. J. Dis. Child., 67, 463. Rubin, H. T., and Hobart, H. M. (1940). Arch. Paediat., 57, 410.

Kornblum, K. (1944). Amer: J. Roentgen., 51, 292.

Kramer, R., and Glass, A. (1932). Ann. Otol. Laryng. etc. St. Louis, 41, 1210.

Laennec, R. T. H. Treatise on Diseases of the Chest and on Mediate Auscultation. 1823. London.

Lapin, J. H. (1943). Whooping Cough. C. C. Thomas. Springfield, Illinois. 
Lee Lander, F. P., and Davidson, M. (1938). Brit. J. Radiol., 11, 65.

(1946). 'Thorax, 1, 198.

- (1936). Proc. R. Soc. Med., 29, 1383.

Lemon, W. S. (1926). Med. Clin. N. Amer., 10, 531.

Leys, D. G. (1927). Chronic Pulmonary Catarrh. H. K. Lewis. London.

Lictheim, L. (1878). Arch. exp. Path. Pharmokol., $10,54$.

Lisa, J. R., and Rosenblatt, M. B. (1943). Bronchiectasis. Oxford University Press. London.

Lloyd, M. S. (1931). Amer. Rev. Tuberc., 23, 476.

Louis, P. C. A. (1826). Memoires, ou Recherches Anatomico-pathologique, etc. Paris.

Marcy, C. H. (1937). Internat. Clinic., 1, 144.

McNeil, C., Macgregor, A. R., and Alexander, W. A. (1929). Arch. Dis. Childh., 4, 170.

Mendelssohn, A. (1845). Der Mechanismus der Respiration. Berlin.

Miller, J. A. (1934). J. thorac. Surg., 3, 246.

Miller, W. S. (1947). The Lung. C. C. Thomas. Springfield.

Moll, H. H. (1932). Quart. J. Med. n.s., 1, 457.

Neil, J. H., Gilmour, W., and Gwynne, F. J. (1937a). Ann. Otol. etc. St. Louis, 46, 338.

- (1937b). Med. J. Aust., 2, 165.

Nelson, H. P. (1934). Brit. med. J., 2, 251.

Ogilvie, A. G. (1941). Arch. int. Med., 68, 395.

Oswald, N. C. (1947). Proc. R. Soc. Med., 40, 736.

Ochsner, A. (1929). J. Amer. med. Ass., 93, 188.

Pasteur, W. (1908). Lancet, 2, 1351.

- (1914). Ibid., 1, 1428.

-_ (1914). $\quad$ Brit. J. Surg., 1, 587.

Perry, K. M. A., and King, D. S. (1940). Amer. Rev. Tuberc., 41, 531 .

Pospischill, D. (1921). Uber Klinik und Epidemiologie der Pertussis. Berlin.

Punch, A. L. (1940). Lancet, 1, 5.

Raia, A. (1938). Amer. Jour. Dis. Childh., 56, 852.

Raymond, A. (1835). Mem. Acad. Roy. Med. Paris, 14, 117.

Riggins, H. M. (1941). Amer. J. Surg., 54, 50.

Rilliet, F., and Barthez, E. (1843). Traité Cliniques et Pratiques des Maladies des Enfants. Paris. Vol. 1.

Robinson, W. L. (1933). Brit. J. Surg., 21, 302.

Rubin, E. H. (1947). Diseases of the Chest. W. B. Saunders. Philadelphia.

Sante, L. R. (1927). Radiology, 8, 1.

Scott, W. J. M. (1925). Arch. Surg., 10, 73.

Schneider, H. (1927). Erwokene. Bronchiectasie. Ziegler. Beitr. path. anat., 79, 466.

Singer, J. J., and Graham, E. A. (1926). Amer. J. Roentgen., 15, 54.

Stokes, W. (1882). A Treatise on Diagnosis and Treatment of Diseases of the Chest, p. 129.

Swift, P. N. (1948). Lancet, 1, 133.

Tannenberg, J. R., and Pinner, M. (1942). J. thorac. Surg., 11, 571:

Thorpe, E. S. (1929). Amer. J. med. Sci., 177, 759.

Traube, L. (1846). Beitr. z. exper. Path. Physiol., 1, 65.

Vining, C. W. (1943). Practitioner, 4, 205.

Wall, C. and Hoyle, J. C. (1932). Brit. med. J., 1, 597.

Warner, W. P. (1935). Amer. med. Ass., 105, 1666.

Warner, W. P. (1935). Amer. med. Ass.,

Warner, W. P., and Graham, D. (1933). Arch. int. Med., 52, 888 .

Wearing, J. D. H. (1948). Lancet, 1, 822.

Weinberg, J. (1937). J. thorac. Surg., 6, 402.

Wilson, R. W. (1939). J. Paediat., 14, 368. 